\title{
I 917.73265
}

GOOS 4

c. 3

13706275
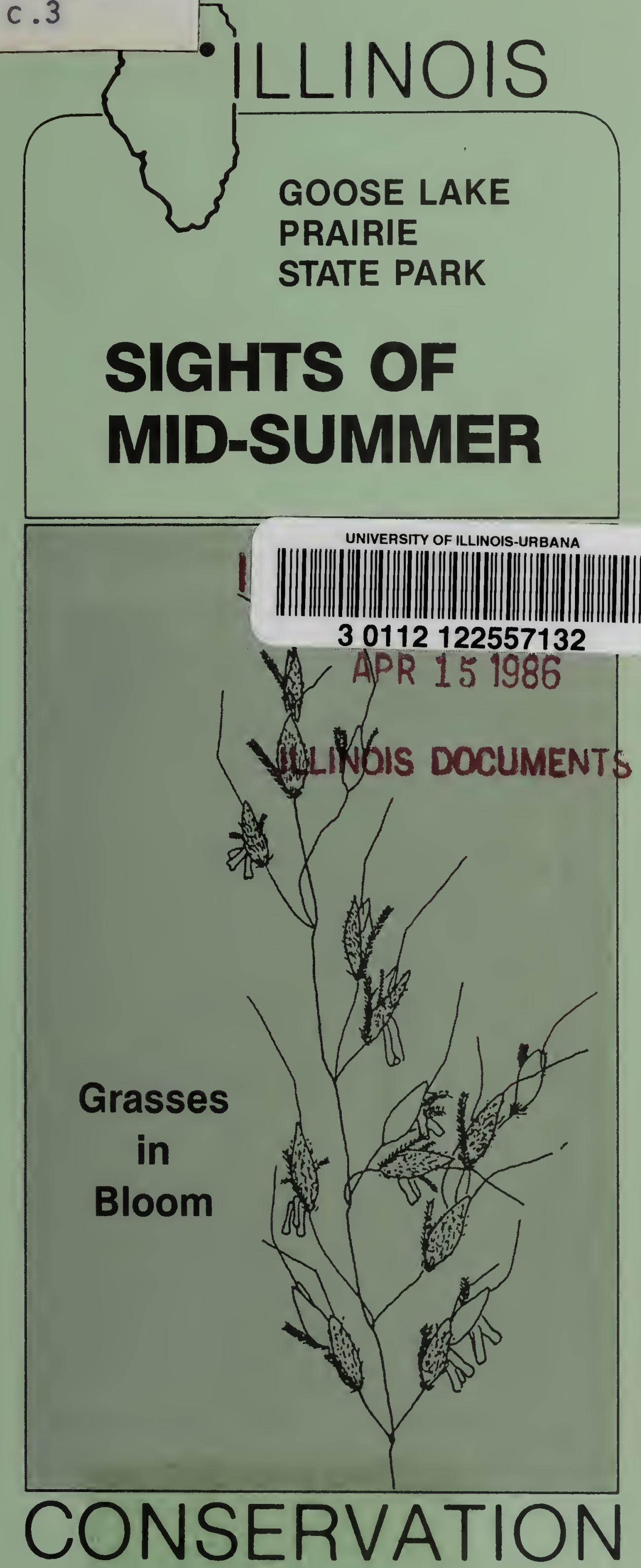
Some of the most interesting prairie flowers are the grasses. That's right! Grasses are flowers too. But they're small, so look closely. And don't forget to bring a magnifying glass. Since the flowers are wind pollinated they lack the showy array of petals that is found among the forbs. Instead, their beauty lies in the intricate detail of their delicate structures.

NORTHERN PRAIRIE DROPSEED

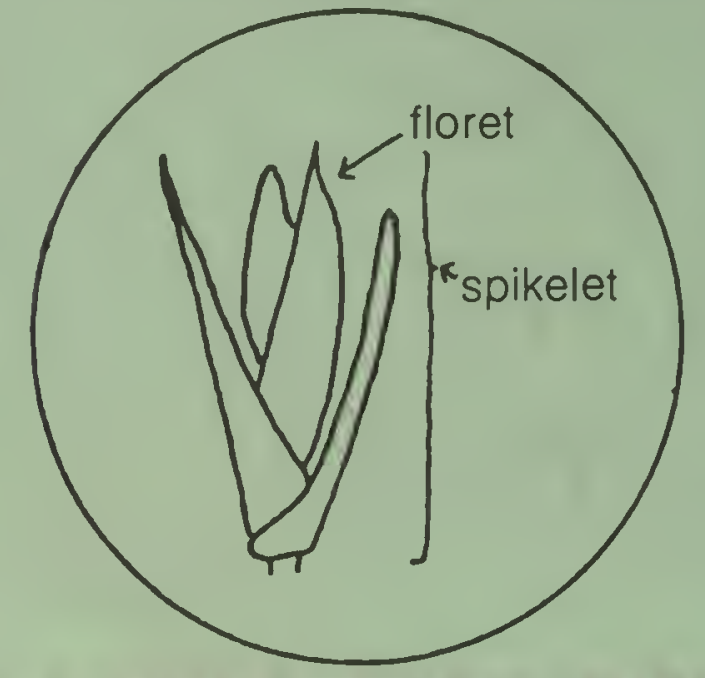

this unit is called a a spikelet? Grasses in bloom seem to explode open so the wind may carry pollen from another [0] to stigma [q]. The seed develops in the pistil of the floret.

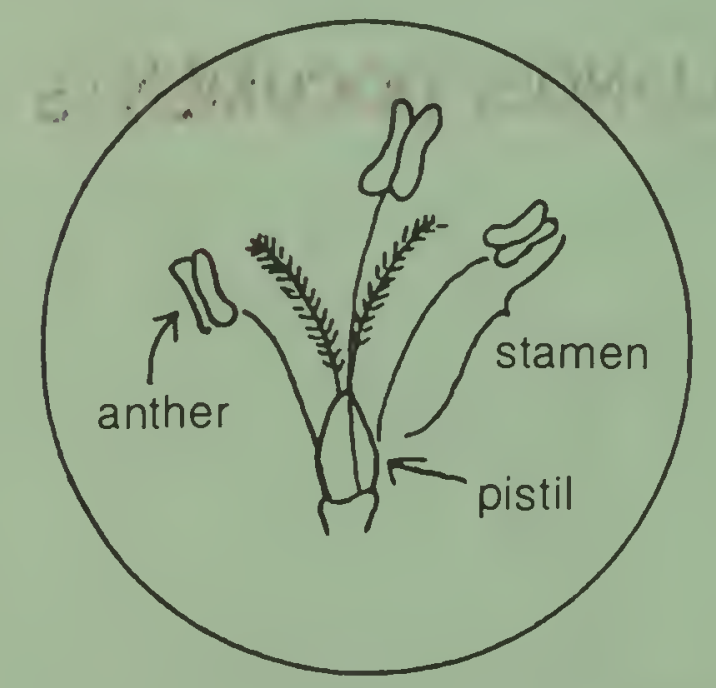

NORTHERN PRAIRIE DROPSEED

A grass flower is called a floret. Florets grow either singly, as in Northern Prairie Dropseed (on the left), or in bunches, like Canada Wild Rye. Two tiny modified leaves cup the floret;
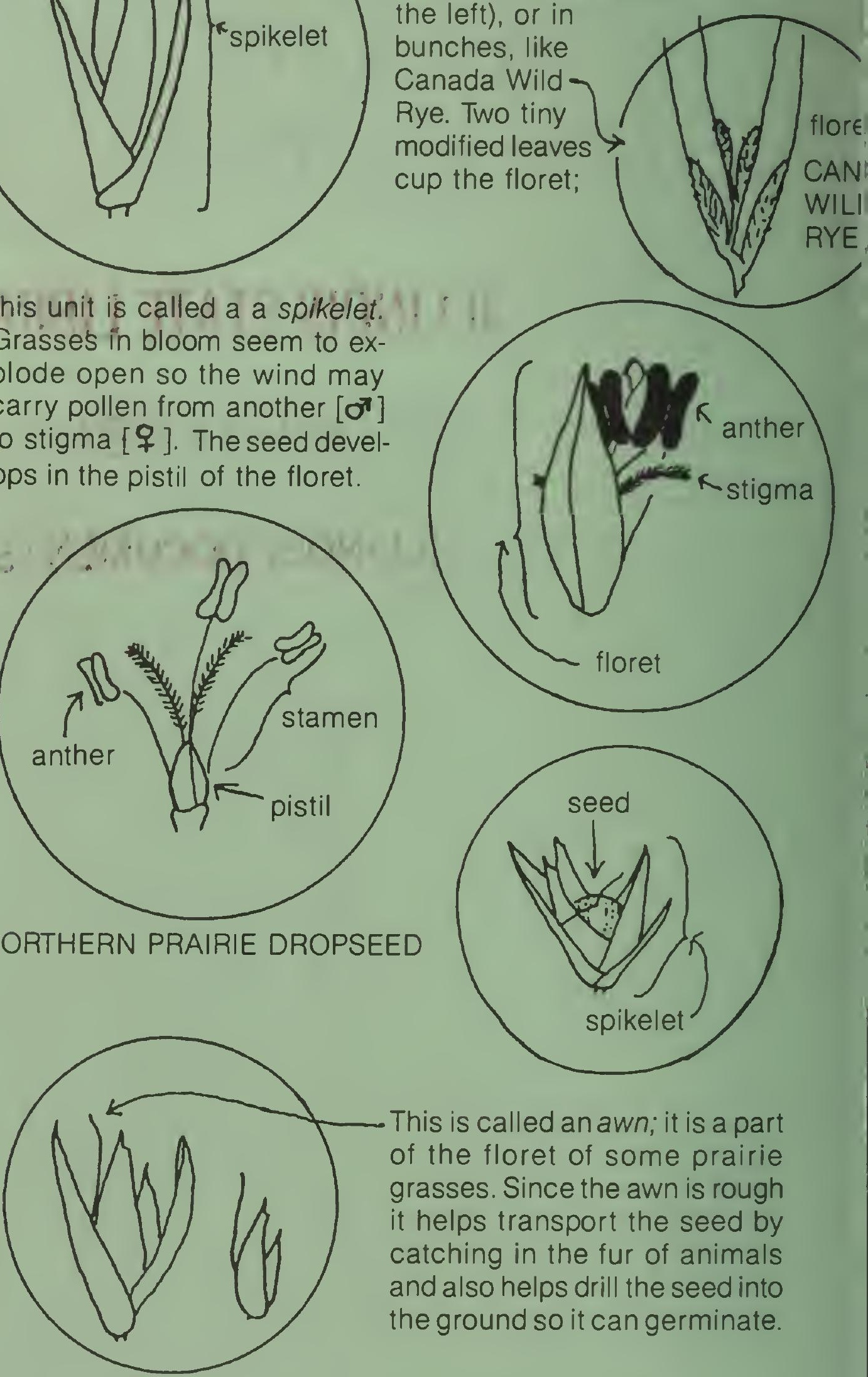

This is called an awn; it is a part of the floret of some prairie grasses. Since the awn is rough it helps transport the seed by catching in the fur of animals and also helps drill the seed into the ground so it can germinate.

BLUEJOINT

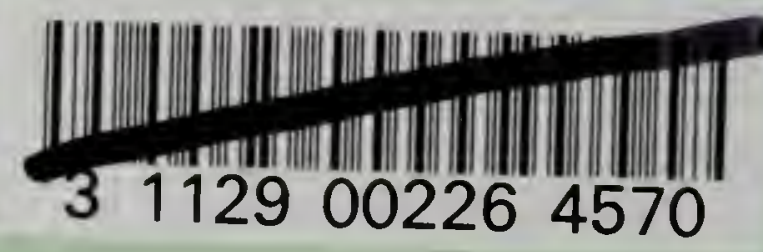


The spikelets and the arrangement of the spikelets are characteristic for a species. Spikelets are borne on the inflorescence (which is the seed head). Oftentimes it is the inflorescence of a grass that most people are familiar with. You can learn to recognize grasses at a distance by their seed heads. When you are not exactly certain what kind of grass you are looking at, another character to look at is the ligule, which occurs at the junction of leaf sheath and leaf blade.

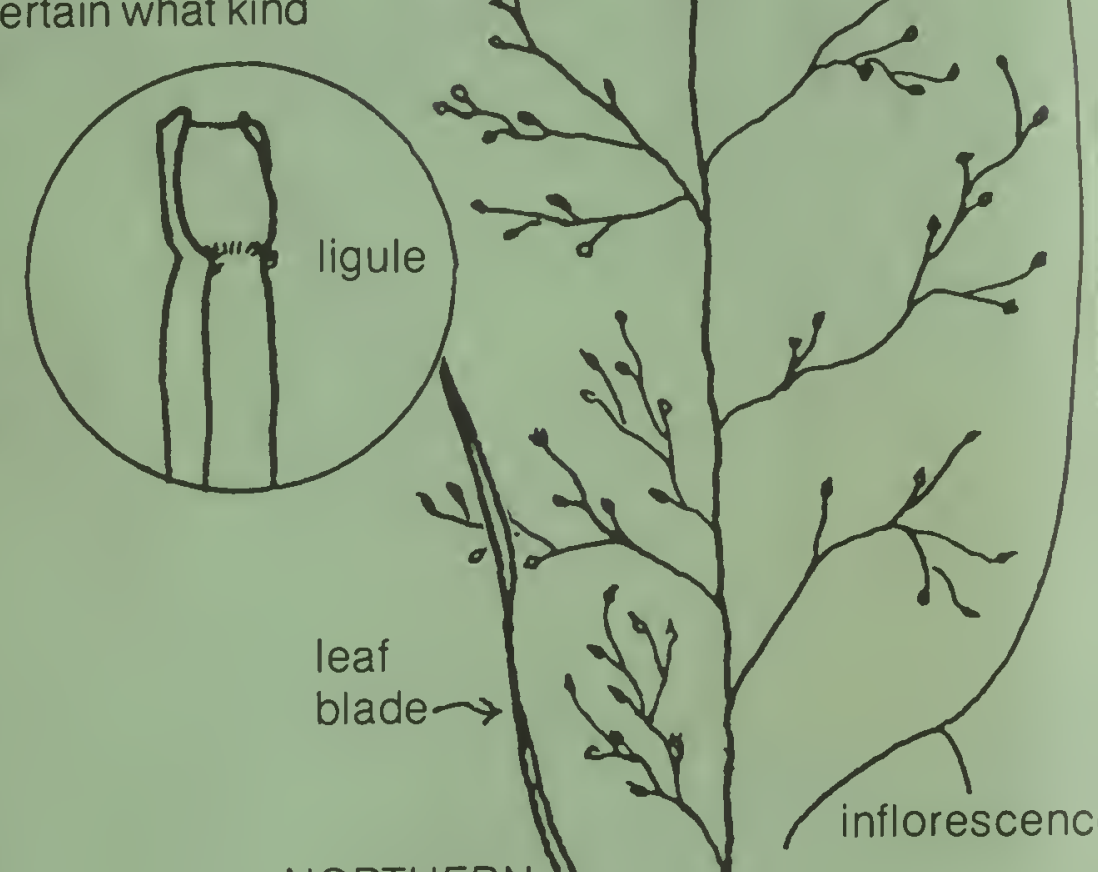

Sometime in mid-summer, the grasses begin producing a magnificent spectacle of countless tiny

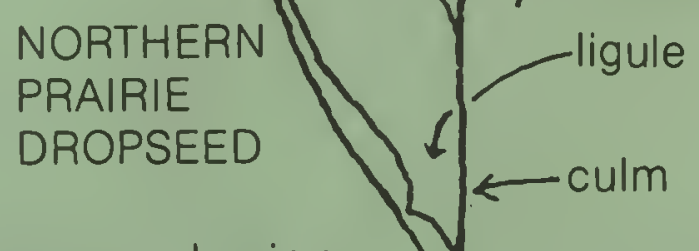
blooms that dot the prairie with bright color. The inflorescences are tossed by the breezes, and sometimes here, sometimes there, a splash of orange or yellow shows among the green. Following are illustrations of some of our most common prairie grasses at Goose Lake Prairie.

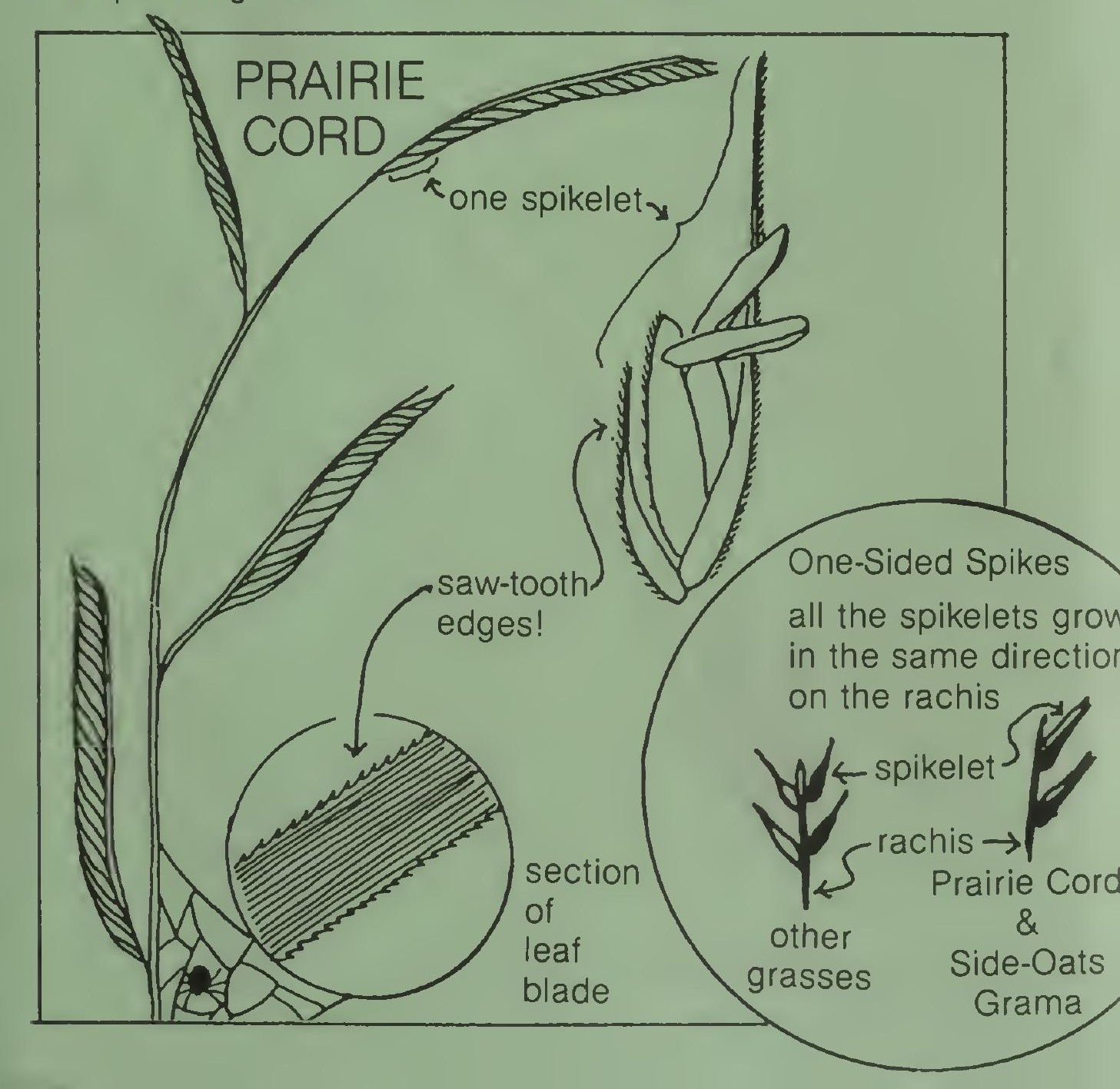




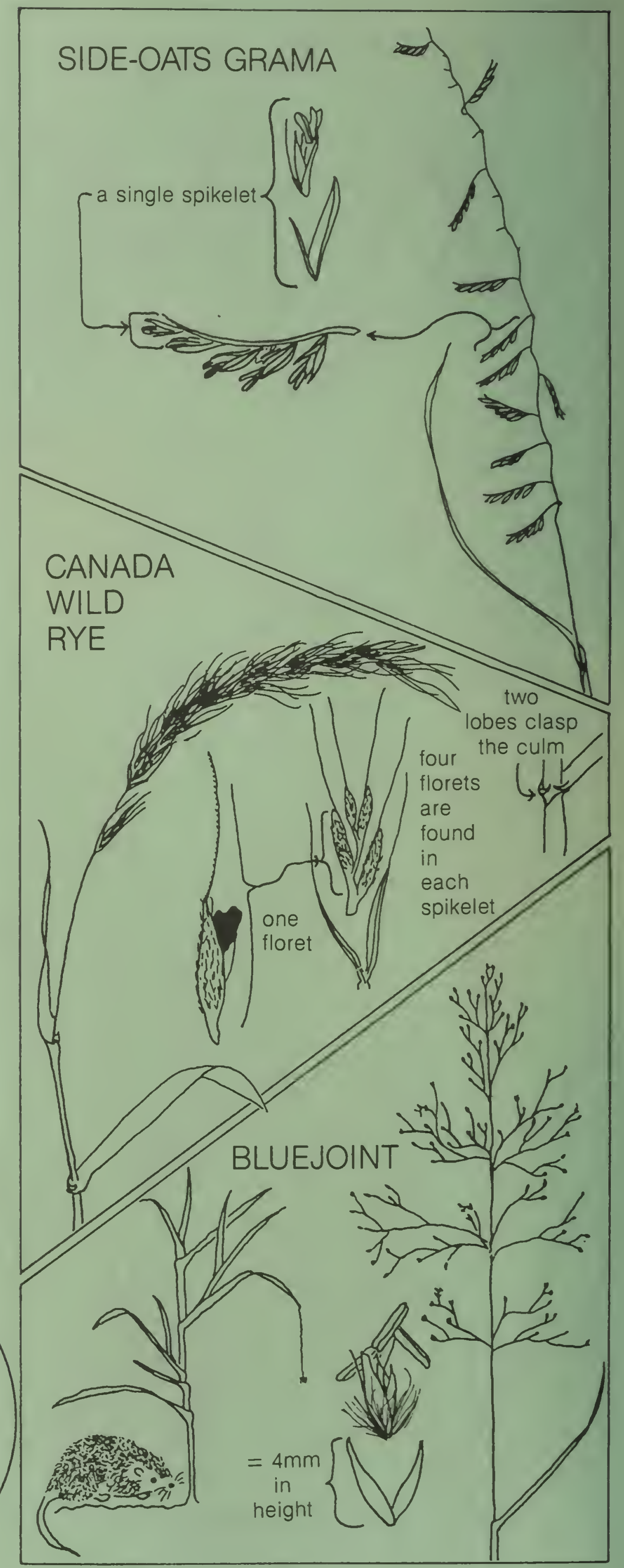




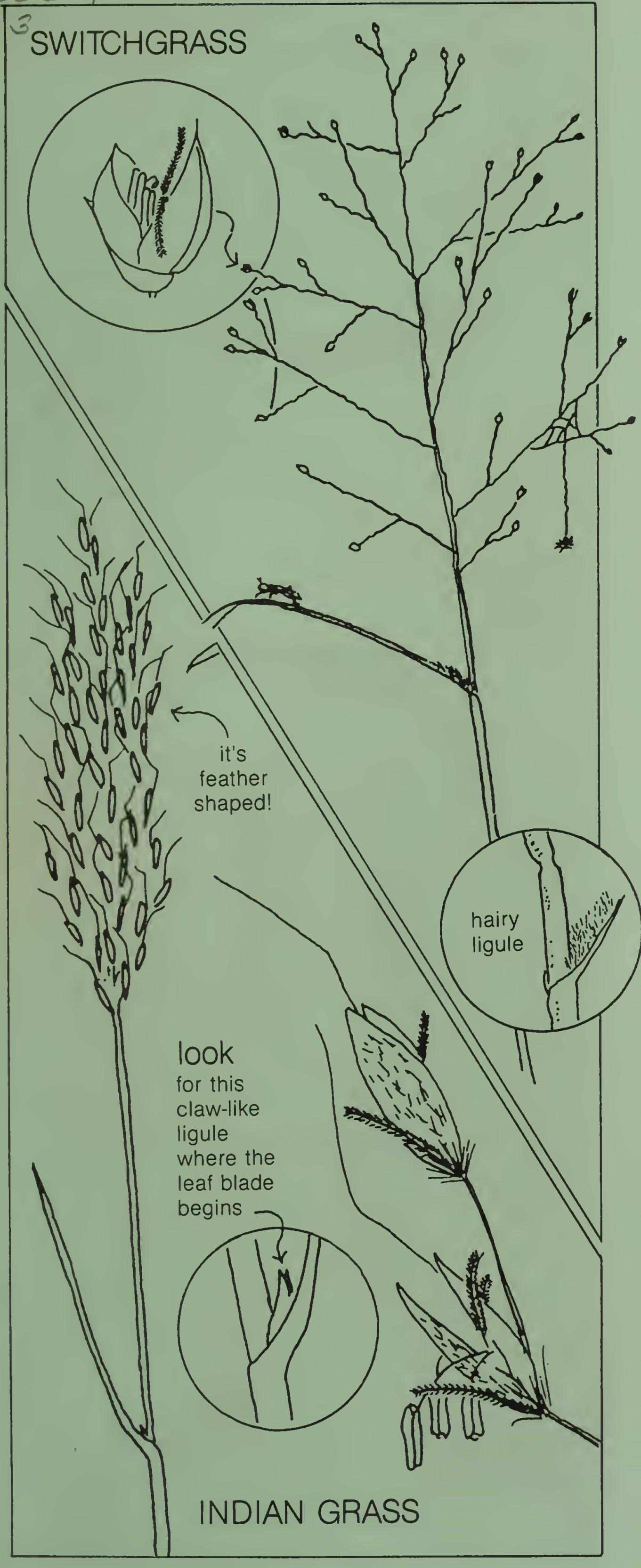




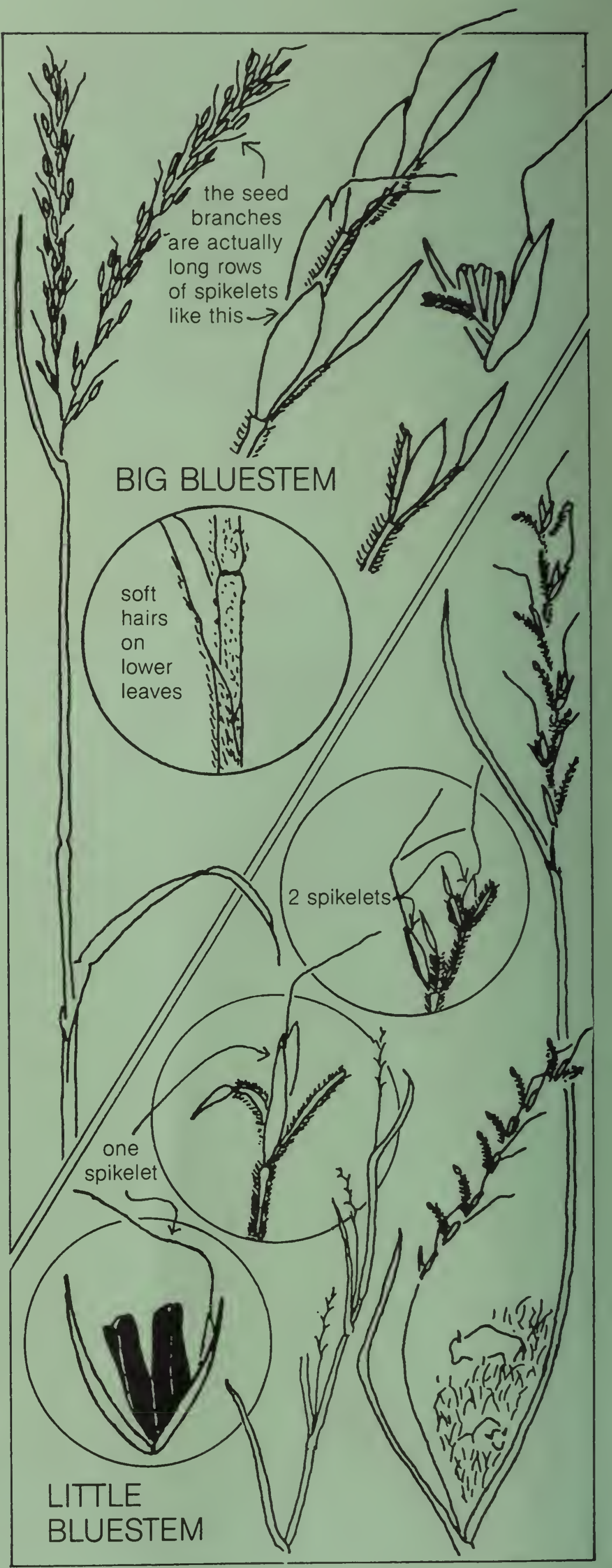

